\title{
Conversation Club: Espaço para Prática da Oralidade em Inglês e Troca de Experiências
}

\section{Conversation Club: A Club for English Speaking Practice and Exchange of Experiences}

\author{
Caroline Chioquetta Lorenset ${ }^{1}$ \\ Denize Nobre-Oliveira ${ }^{2}$ \\ Moisés Carlos Bahiense Bernardino ${ }^{3}$ \\ Gabriela Macedo de Aguiar ${ }^{4}$
}

\begin{abstract}
Resumo
Este relato de experiência é resultante de um projeto de extensão intitulado "Conversation Club", que visou capacitar os participantes a desenvolverem a habilidade da fala de inglês como língua estrangeira através da prática da oralidade, bem como através da habilidade de listening (escuta). No projeto, novas oportunidades foram propostas para que os participantes pudessem praticar ambas habilidades através de encontros semanais com duração de uma hora. Além da melhora nas habilidades linguísticas e das trocas interculturais que aconteciam durante os encontros, observamos que os benefícios de praticar uma língua estrangeira compreendem aspectos não apenas profissionais e/ou acadêmicos, mas também aspectos pessoais. O projeto Conversation Club possui não apenas um viés pedagógico, mas também como uma forma de autocuidado durante tempos de pandemia e distanciamento social.
\end{abstract}

Palavras-chave: Clube de conversação. Inglês como língua estrangeira. Projeto de Extensão.

\begin{abstract}
This article is the result of an extension project at IFSC, the Conversation Club, whose main objective was to develop participants' speaking ability in English as a Foreign Language through an oral-aural approach. Every week, new topics were proposed in order to practice both abilities (speaking and listening) during the one-hour on-line meetings. Besides the improvement in the linguistic aspect, and the intercultural exchange, we observed that the benefits of studying a foreign language are beyond professional and/or academic purposes. Not only does this project have a pedagogical aspect, but it is also a way of self-care during these times of pandemic and social distancing.
\end{abstract}

Keywords: Conversation Club. English as a Foreign Language. Extension Project.

\section{Introdução}

1 Doutorado em Linguística (UFSC). Instituto Federal de Santa Catarina, Florianópolis, Santa Catarina, Brasil. Orcid: https://orcid.org/0000-0002-1999-0134. E-mail: caroline.lorenset@ifsc.edu.br.

2 Doutorado em Letras (UFSC). Instituto Federal de Santa Catarina, Florianópolis, Santa Catarina, Brasil. Orcid: https://orcid.org/0000-0002-1480-0848. E-mail: denize@ifsc.edu.br.

3 Graduando em Letras Português e Inglês (UFSC). Instituto Federal de Santa Catarina, Florianópolis, Santa Catarina, Brasil. Orcid: https://orcid.org/0000-0001-7319-6655. E-mail: moises.bernardino@ifsc.edu.br.

${ }^{4}$ Graduanda em Design Gráfico (IFSC). Instituto Federal de Santa Catarina. Florianópolis, Santa Catarina, Brasil). Orcid: https://orcid.org/0000-0003-0868-6951. E-mail: gabmacedo.aguiar@gmail.com. 
O projeto de extensão Conversation Club vem sendo ofertado desde 2015 no IFSC Campus Florianópolis, tendo concluído até o momento quatro edições com duração de um semestre cada uma. Este projeto visa capacitar os participantes a desenvolverem a habilidade da fala em inglês como língua estrangeira através da prática da oralidade, bem como através da habilidade de escuta. Com o objetivo principal de oportunizar a prática da língua inglesa na modalidade oral a fim de atender as demandas da comunidade interna e externa, buscou-se, especificamente, i) oferecer um espaço para a prática da língua inglesa; ii) desenvolver e/ou consolidar os conhecimentos linguísticos, habilidades de pronúncia e fluência na comunicação oral dos participantes; iii) trabalhar aspectos interculturais por meio das rodas de conversa; iv) praticar a habilidade de escuta em língua inglesa; e v) estudar questões sobre a pronúncia da língua inglesa.

No nosso mundo globalizado, os benefícios de aprender um novo idioma vão além de questões profissionais. Já é comprovado o benefício cognitivo e biológico proporcionado pelo aprendizado: melhoria da plasticidade cerebral, melhoria na tomada de decisões, aumento da criatividade, reforço e criação de novas conexões neurais, contribuindo para prevenção de doenças neurológicas degenerativas como o Mal de Alzheimer, por exemplo (MARTENSSON et al., 2012). Estudos mostram também que a exposição de aprendizes a uma língua estrangeira em si já serve como gatilho para uma melhora tanto da habilidade de listening quanto da habilidade de fala (ROCHET, 1995; YAMADA et al., 1996; BRADLOW et al., 1997; HARDISON, 2002; WANG, 2002; HAZAN et al., 2005; NOBRE-OLIVEIRA, 2007).

No âmbito institucional, capacitar os servidores TAEs, docentes e discentes em língua inglesa contribui para, por exemplo, aumentar a autonomia por parte dos servidores ao atender e explicar processos a alunos intercambistas e comitivas estrangeiras, e para a ampliação do conhecimento linguístico dos discentes. Além disso, o conhecimento de outras culturas permite o desenvolvimento de habilidades interpessoais, tais como criatividade, colaboração, flexibilidade, relacionamento interpessoal, dentre outras. Por consequência, o desenvolvimento dessas habilidades promove o acolhimento ao outro e a compreensão do diferente, estreitando a distância entre culturas.

O Conversation Club também foi pensado para atuar como um espaço de networking no qual, numa instituição com as proporções do Campus Florianópolis, servidores possam conhecer-se e interagir entre si, bem como com os demais frequentadores (discentes e comunidade externa).

\section{Os encontros}

LínguaTec, Instituto Federal de Educação, Ciência e Tecnologia do Rio Grande do Sul, Bento Gonçalves 
Os encontros do clube de conversação na edição de 2020.1 tiveram uma hora de duração e aconteceram duas vezes por semana, totalizando dezenove encontros. Inicialmente, os encontros haviam sido planejados para acontecerem presencialmente, porém, devido à pandemia mundial da COVID-19, ocorreram virtualmente de forma síncrona pela plataforma Google Meet.

Para a divulgação do projeto de extensão $0^{5}$, optou-se pelo meio virtual, especialmente através de chamadas semanais nas redes sociais (Instagram e Facebook), além de e-mails enviados para os servidores do IFSC (Figura 1).

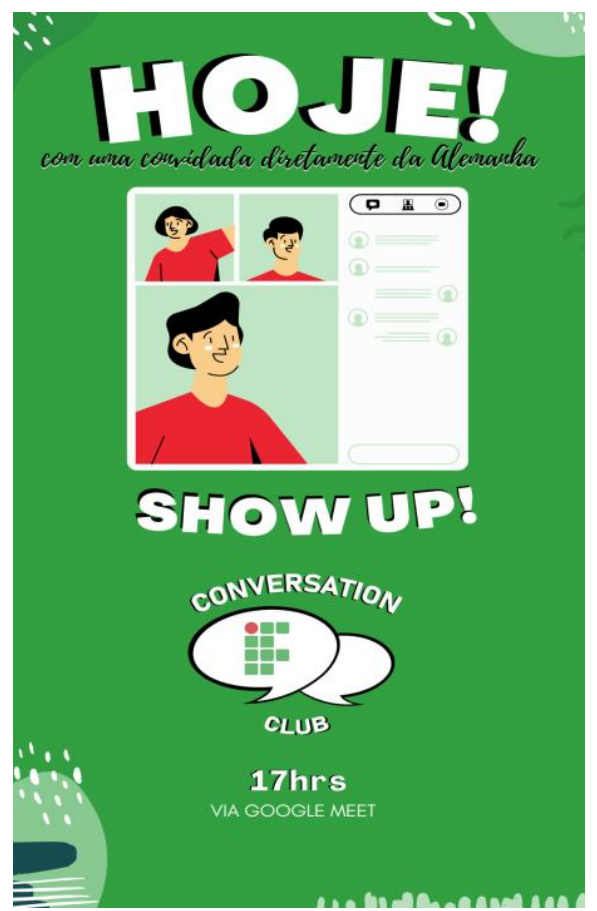

Figura 1. Exemplo de cartaz de divulgação do encontro do Conversation Club.

Fonte: acervo do projeto de extensão.

Em função da característica virtual e síncrona dos encontros do projeto, tanto pessoas de outras cidades além de Florianópolis/SC puderam participar (tivemos participação de pessoas de Xanxerê/SC, Tubarão/SC, Itajaí/SC, São José/SC, Balnerário Camboriú/SC, Fortaleza/CE), quanto pessoas de outros países (México, Itália, Alemanha, Colômbia e Peru). Durante os encontros, foram discutidos temas variados sugeridos pelos facilitadores, que foram eventualmente abordados através de imagens, músicas e vídeos. Em média, cerca de dez participantes estavam presentes nos encontros.

5 O projeto de extensão Conversation Club (edição do ano de 2020) foi contemplado pelo Edital 18 / 2019 / PROEX / PROPPI IFSC Campus Florianópolis. 
Aspectos relacionados a vocabulário, pronúncia, uso da língua inglesa e cultura foram abordados quando necessário. Tanto as habilidades técnicas quanto as interpessoais (pensamento crítico e criativo, tomada de decisões, liderança, paciência, empatia, flexibilidade, solução de problemas, trabalho em equipe, etc.) foram trabalhadas através da interação social de cada encontro do projeto.

Neste projeto de extensão aplicado no ano de 2020, a equipe idealizadora era formada por duas docentes de língua inglesa do IFSC Campus Florianópolis, um técnico-administrativo que atuava no IFSC Campus Xanxerê, e também uma bolsista discente. A aluna bolsista atuou como facilitadora dos encontros, orientada pelas professoras supervisoras, participando também de outros aspectos operacionais do projeto. A bolsista foi selecionada após chamada interna 6 no Campus Florianópolis, onde o principal objetivo era encontrar um discente do campus que falasse inglês fluente e tivesse disponibilidade e interesse para realizar as atribuições que the seriam designadas. Dentre essas atribuições estavam: a) planejar os temas de cada encontro (sob supervisão e em conjunto com as professoras), propondo temas e atividades; b) coordenar e/ou facilitar as discussões durante os encontros do Conversation Club; c) organizar e planejar o ambiente de ensino onde aconteceram os encontros; d) auxiliar a professora coordenadora na elaboração de relatórios; e) divulgar o projeto e os encontros semanais. Para desempenhar essas atribuições, a aluna bolsista dedicou às atividades do projeto um total de 20 horas semanais.

Além disso, o servidor técnico-administrativo atuou como facilitador dos encontros em parceria com a aluna bolsista. Suas atribuições foram principalmente as de planejar, facilitar e participar dos encontros semanais levando em consideração suas experiências anteriores com clubes de conversação internacionais.

No decorrer dos encontros, foram convidados alguns estrangeiros que não possuem a língua inglesa como língua nativa com a intenção de demonstrar que o inglês falado não precisa ser aquele que por muitos é considerado o "perfeito" (tomando como modelo o falante nativo, no qual intrinsecamente há uma relação de poder entre o "dono da língua" e o falante não-nativo), mas sim que diversas pessoas podem usar o inglês como língua franca, com seus sotaques e suas identidades como peças-chave no processo comunicativo (NELSON, 2011). Os convidados estrangeiros eram todos da mesma faixa etária, entre 25 e 30 anos, totalizando 5 convidados estrangeiros (um por encontro).

Por fim, observamos que, embora o projeto tenha sido planejado para ser executado presencialmente, a vantagem dos encontros virtuais foi a possibilidade de alcance de pessoas fora da

\footnotetext{
${ }^{6}$ A chamada interna para seleção da bolsista foi contemplada pelo Edital N ${ }^{0}$ 01/2020 de 10 de fevereiro de 2020 - Assessoria de Línguas Estrangeiras /DALTEC, IFSC Campus Florianópolis.
} 
cidade do Campus Florianópolis e até do país. A participação de estrangeiros foi importante para treinar a compreensão de diferentes sotaques e trocar informações sobre diferentes culturas e costumes de cada país (como hábitos, comidas típicas e até mesmo palavras da própria língua nativa do falante).

\section{Conclusão}

Na execução do projeto, a integração entre ensino e extensão se deu através da articulação com um dos públicos-alvo do Conversation Club, a comunidade externa, que teve a oportunidade de praticar a língua inglesa para fins comunicativos. 0 sucesso do projeto atual e de suas edições anteriores (entre 2015 e 2017) foi corroborado pela boa receptividade que teve tanto pelos servidores, discentes e comunidade externa. Mesmo com a dificuldade encontrada na mudança do formato (de presencial para virtual síncrono devido à pandemia), conforme explicado anteriormente, os encontros aconteceram de forma on-line e síncrona.

Constatou-se, ademais, que o projeto Conversation Club, além de ter trazido inúmeros benefícios para o bem-estar dos participantes, pois era um momento de descontração e aprendizagem, também foi um espaço onde os participantes puderam praticar suas habilidades linguísticas e interpessoais. Levando isso em consideração, da parte das professoras organizadoras, há a intenção em continuar o projeto no futuro para novas edições.

Por fim, apesar do desafio inicial de transformar uma atividade concebida para ser realizada presencialmente em uma atividade remota, o resultado foi extremamente positivo, pois possibilitou a participação de um público diverso, enriquecendo consideravelmente as trocas linguísticas e culturais.

\section{Referências}

BRADLOW, A. R. et al. Training Japanese listeners to identify English /r/ and II: IV. Some effects of perceptual learning on speech production. Journal of the Acoustical Society of America, v. 101, p. 22992310, 1997. https://doi.org/10.1121/1.418276

HARDISON, D. Transfer of second-language perceptual training to production improvement: focus on $/ r /$ and /I/. New Sounds 2000: Proceedings of the fourth international symposium on the acquisition of second language speech, Klagenfurt, Austria: University of Klagenfurt, p.166-173, 2002.

HAZAN, V. et al. Effect of audiovisual perceptual training on the perception and production of consonants by Japanese learners of English. Speech Communication, v. 47, p. 360-378. 2005. https://doi.org/10.1016/j.specom.2005.04.007 
MARTESSON, J. E. et al. Growth of language-related brain areas after foreign language learning. Neurolmage, v. 63, n. 1, p. 240, 2012. https://doi.org/10.1016/j.neuroimage.2012.06.043

NELSON, C. L. Intelligibility in World Englishes: Theory and Application. New York: Routledge, 2011.

NOBRE-OLIVEIRA, D. The effect of perceptual training on the learning of English vowels by Brazilian Portuguese speakers. Unpublished Doctoral Dissertation. Florianópolis, SC: Universidade Federal de Santa Catarina. 2007.

ROCHET, B. Perception and production of second-language speech sounds by adults. In: STRANGE W. (Ed.). Speech perception and linguistic experience: Issues in cross-language research. Timonium, MD: York Press, 1995.

WANG, X. Training Mandarin and Cantonese speakers to identify English vowel contrasts: long term retention and effects on production. Unpublished doctoral dissertation. Simon Fraser University. 2002.

YAMADA, R. A. et al. Does training in speech perception modify speech production? Proceedings of the fourth International Conference on Spoken Language Processing. Wyndham Franklin Plaza Hotel, Pennsylvania. Philadelphia: Institute of Electrical and Electronics Engineers, v. 2, p. 606-609, 1996. https://doi.org/10.1109/ICSLP.1996.606911

Data de submissão: 26/07/2021. Data de aprovação: 25/10/2021. 